\title{
DSCR9 gene simultaneous expression in placental, testicular and renal tissues from baboon (papio hamadryas)
}

\author{
Irám Pablo Rodriguez-Sanchez ${ }^{1,2}$, María Lourdes Garza-Rodríguez ${ }^{2}$, María Elizabeth Tejero ${ }^{3,4}$, Shelley A Cole , \\ Anthony G Comuzzie ${ }^{3}$ and Hugo Alberto Barrera-Saldaña $a^{1,2^{*}}$
}

\begin{abstract}
Background: In 2002 Takamatsu and co-workers described the human DSCR9 gene and observed that it was transcriptionally active in human testicular tissue, but no protein was identified as a product of this transcript. Similar results were obtained in chimpanzee tissue. This gene has not been detected in species other than primates, suggesting that DSCR9 is exclusively found in these mammals.
\end{abstract}

Results: We report evidence of DSCR9 expression in placenta, testis and kidney of baboon (Papio hamadryas). We used primers specific for DSCR9 to amplify transcripts through reverse transcription (RT) coupled to polymerase chain reaction (PCR). Furthermore, PCR was used to amplify the complete DSCR9 gene from genomic DNA from three baboons. We amplified and sequenced five overlapping segments that were assembled into the $3284 \mathrm{bp}$ baboon DSCR9 gene, including the putative promoter and the entire transcriptional unit (5'-UTR, CDS and 3'-UTR).

Conclusions: The baboon DSCR9 gene is highly similar to the human counterpart. The isolated transcripts from baboon tissues (placenta, testis and kidney) of three different baboons correspond to the human orthologous gene.

Keywords: DSCR, Primate, Gene expression

\section{Background}

Down syndrome (DS) or trisomy 21 is the most common chromosome disorder affecting newborns and the most frequent and recognized cause of mental retardation in Homo sapiens (Hosa)[1]. The incidence of this syndrome is about 1 in 700 newborns [2]. Chromosome 21 is the smallest of human autosomal chromosomes, and an extra copy or additional segment of this chromosome causes DS [3]. The chromosomal region responsible for this pathology has been described [4] and named Down Syndrome Critical Region (DSCR)[5,6]. By comparing the genomic DSCR sequence in humans with that of other species, it was shown that it is highly conserved in great apes[6] and similar trisomies have been described

\footnotetext{
* Correspondence: hugo.barrera@uanl.mx

'Vitaxentrum. Blvd. Puerta del Sol 1005, Colinas de San Jerónimo, Monterrey, Nuevo León 64460, Mexico

${ }^{2}$ Facultad de Medicina, Departamento de Bioquímica y Medicina Molecular, Universidad Autonoma de Nuevo León, Av. Madero y Dr. Aguirre Pequeño, Col. Mitras Centro, Monterrey, Nuevo León 64460, Mexico

Full list of author information is available at the end of the article
}

in these non human primates $[7,8]$. In humans, ten potential genes have been identified in the DSCR, two of which (DSCR9 and DSCR10) are exclusive of primates [9]. In man, DSCR9 gene transcription, but not proteins, were evidenced in testicle; this was also demonstrated in chimpanzee [9]. The aim of this study was to identify the chromosome segment from which the DSCR9 gene's transcripts originated.

We amplified five segments from the baboon genome using primers designed to render overlapping amplicons. Using this strategy we were able to assemble the complete DSCR9 gene of the species. The isolated genomic segment includes the putative promoter and the complete transcriptional unit. Using reverse transcription (RT) coupled to polymerase chain reaction (PCR), we have gathered evidenced of the expression of the DSCR9 gene in baboon's placenta, testicles, and kidney, an of its lack of detectable expression in heart, omental fat, skeletal muscle, pancreas, mononuclear cells, liver, and hypothalamus. The identified transcripts of these tissues

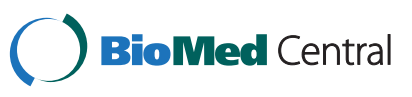


in three different individual were identical and correspond to the isolated DSCR9 baboon gene.

\section{Methods}

\section{Animal specimens}

Animal procedures were performed according to ethical guidelines and reviewed by the Institutional Animal Care and Use Committee of the Texas Biomedical Research Institute (TBRI). Animals were maintained at the Southwest National Primate Research Center in San Antonio, Texas at TBRI. All the animals shared the same diet and environmental conditions before and during pregnancy. All baboons are gang-housed and fed ad libitum on a standard low-fat chow diet (Harlan Tecklad 15\% Monkey Diet, 8715).

\section{Biological samples}

Different tissues from tree male baboons (testis, kidney, heart, omental fat, skeletal muscle, pancreas, mononuclear cells, liver, and hypothalamus) and from tree female baboons (ovary and placenta) were collected in programmed necropsies, under fasting conditions. Placental tissues were collected by caesarean section at the time of birth [at the term period of gestation for this species (136 to 139 days)]. All tissues were stored in liquid nitrogen immediately after collection until needed.

\section{Nucleic acid isolation from placental tissue}

Genomic DNA and total RNA were isolated from each tissue using TRIZOL reagent; procedures were performed according to the manufacturer's instructions (Invitrogen, Carlsbad, CA). RNA samples were treated with DNase I (Invitrogen) for $10 \mathrm{~min}$ at $37^{\circ} \mathrm{C}$ to remove traces of genomic DNA, genomic DNA was treated with RNase I (Invitrogen) for $30 \mathrm{~min}$ at $37{ }^{\circ} \mathrm{C}$ to remove traces of RNA. RNA and DNA quality and integrity were assessed by standard spectrophotometric and electrophoretic methods, respectively.

\section{Reverse transcription}

RT reactions were carried-out with $1 \mu \mathrm{g}$ of total RNA using random primers and a High-capacity cDNA Reverse Transcription kit, following manufacturer's instructions (Applied Biosystems, Foster City, CA).

\section{Primer design}

To amplify baboon DSCR9 gene and transcript, primers were designed based on highly conserved primate DSCR9 sequences previously reported [great apes and old world monkeys (OWMs)] and using the online primer-3 tool [10]. Primers (see Table 1) were designed to amplify overlapping target template sequences in order to isolate the complete DSCR9 gene (in concordance with human gene structure).

\section{PCR amplification}

To amplify DSCR9 gene from genomic DNA five primer sets were used in separate PCR reactions (Table 1). Each PCR reaction was performed in $50 \mu$ reaction containing $10 \mathrm{pM}$ of each primer, $200 \mathrm{ng}$ of genomic DNA and 2X PCR master mix (Qiagen, Valencia, CA). To amplify DSCR9-related transcript, a primers set (see Table 1) was used with $10 \mathrm{pM}$ of each primer and $5 \mu \mathrm{l}$ of RT reaction from each tissue. PCR amplification programs are described in Table 1. Universal $18 \mathrm{~s}$ ribosomal gene primers were used in RT-PCR as positive control. (Ambion, Austin, TX). PCR amplifications were confirmed by electrophoresis in agarose gel (1\%) run in TAE X1 buffer, stained with etidium bromide and visualized under UV light.

\section{Molecular cloning and sequencing}

PCR products were cloned using the TOPOXL cloning system with the pCR-XL-TOPO $3.5 \mathrm{~kb}$ vector (Invitrogen). Ligation reactions were transformed into electrocompetent Top 10 Escherichia coli bacterium according to the manufacturer's instructions (Invitrogen). Cloning products were sequenced in an ABI PRISM 3100 Genetic Analyzer (Applied Biosystems) using universal M13 primers, and Big Dye terminator reagent (Applied Biosystems). Novel sequence has been deposited in the GenBank database (Accession number: JF775469).

\section{Sequence analysis}

Electropherograms were analyzed using GeneStudio Pro software (GeneStudio, Inc., Suwanee, GA). Procedures were carried out in three clones for each amplicon to exclude artifacts. DNA sequences from DSCR9-related transcripts were used to determine the amino acid sequence using the Transeq online program [11] and were subsequently aligned using the ClustalW program [12] and Vista tools [13]. The alignments were performed using peptide sequences extracted from GenBank [14] by homology search.

\section{Results}

\section{Baboon DCSR9 gene isolation}

Baboon genomic DSCR9 gene was isolated by PCR in five overlapping segments (see Figure 1), which were cloned and sequenced. The assembled sequenced gene was submitted with the BLAST tool of NCBI to the GenBank and match was confirmed with the human DSCR9 gene (data not shown).

\section{DSCR9 gene of papio hamadryas}

The assembled baboon DSCR9 gene lacks a TATA box, conventional Kozak sequence $[15,16]$, introns, and polyadenylation signal. The baboon DSCR9 gene has a structure similar to its human counterpart (Figure 2) but with 


\begin{tabular}{|c|c|c|c|c|c|c|c|c|c|c|c|}
\hline \multirow[t]{2}{*}{ Oligo name } & \multirow[t]{2}{*}{ Oligo sequence } & \multirow[t]{2}{*}{ Orientation } & \multirow[t]{2}{*}{$\begin{array}{l}\text { Primer } \\
\text { set }\end{array}$} & \multirow[t]{2}{*}{$\begin{array}{l}\text { Substrate } \\
\text { to PCR }\end{array}$} & \multirow{2}{*}{$\begin{array}{l}\text { Initial } \\
\text { denatur } \\
\text { alization }\end{array}$} & \multicolumn{3}{|l|}{$\begin{array}{l}\text { Amplification } \\
\text { program }\end{array}$} & \multirow[t]{2}{*}{ Cycles } & \multirow[t]{2}{*}{$\begin{array}{l}\text { Final } \\
\text { elongation }\end{array}$} & \multirow[t]{2}{*}{$\begin{array}{l}\text { Amplicon } \\
\text { size }\end{array}$} \\
\hline & & & & & & Denaturalization & Alignment & Elongation & & & \\
\hline OLIGO-rnaF & CTTGGCGCTAAGCTGCCGC & Forware & \multirow{2}{*}{$\begin{array}{l}\text { AMPLICON } \\
\text {-mRNA }\end{array}$} & \multirow[t]{2}{*}{ mRNA } & \multirow[t]{2}{*}{$94^{\circ} / 3.5 \mathrm{~min}$} & \multirow[t]{2}{*}{$94^{\circ} / 30 \mathrm{seg}$} & \multirow[t]{2}{*}{$60^{\circ} / 45 \mathrm{seg}$} & \multirow[t]{2}{*}{$72^{\circ} / 30 \mathrm{seg}$} & \multirow[t]{2}{*}{42} & \multirow[t]{2}{*}{$72^{\circ} / 15 \min$} & \multirow[t]{2}{*}{$726 \mathrm{pb}$} \\
\hline OLIGO-rnaR & CCTGCTCTGGAGTCTTGGTG & Reverse & & & & & & & & & \\
\hline OLIGO-gene1F & AGCTGGCACTCCCCAGAAT & Forware & \multirow[t]{2}{*}{ OLIGO-gene1 } & \multirow[t]{2}{*}{ gDNA } & \multirow[t]{2}{*}{$94^{\circ} / 5 \min$} & \multirow[t]{2}{*}{$94^{\circ} / 1 \mathrm{~min}$} & \multirow[t]{2}{*}{$60^{\circ} / 45 \mathrm{seg}$} & \multirow[t]{2}{*}{$72^{\circ} / 1 \min$} & \multirow[t]{2}{*}{35} & \multirow[t]{2}{*}{$72^{\circ} / 10 \mathrm{~min}$} & \multirow[t]{2}{*}{$946 \mathrm{pb}$} \\
\hline OLIGO-gene1R & GGCTGAGGCACAGAGAAACT & Reverse & & & & & & & & & \\
\hline OLIGO-gene2F & CTCCCTACCAAAGTGGCTAG & Forware & \multirow[t]{2}{*}{ OLIGO-gene2 } & \multirow[t]{2}{*}{ gDNA } & \multirow[t]{2}{*}{$94^{\circ} / 5 \min$} & \multirow[t]{2}{*}{$94^{\circ} / 1 \mathrm{~min}$} & \multirow[t]{2}{*}{$60^{\circ} / 45 \mathrm{seg}$} & \multirow[t]{2}{*}{$72^{\circ} / 35 \mathrm{seg}$} & \multirow[t]{2}{*}{30} & \multirow[t]{2}{*}{$72^{\circ} / 10 \min$} & 769 pb \\
\hline OLIGO-gene2R & TGTGGAAAGTTGGGGTTTC & Reverse & & & & & & & & & \\
\hline OLIGO-gene3F & GAAAACCCCAACTTTCCACA & Forware & OLIGO-gene3 & gDNA & $94^{\circ} / 5 \min$ & $94^{\circ} / 1 \mathrm{~min}$ & $60^{\circ} / 45 \mathrm{seg}$ & $72^{\circ} / 30 \mathrm{seg}$ & 30 & $72^{\circ} / 10 \min$ & $723 \mathrm{pb}$ \\
\hline OLIGO-gene3R & CCAGGCGAGCAGTCTGTAAC & Reverse & & & & & & & & & \\
\hline OLIGO-gene4F & ССTCTCCTGCAACCAATCAG & Forware & OLIGO-gene4 & gDNA & $94^{\circ} / 5 \min$ & $94^{\circ} / 1 \min$ & $60^{\circ} / 45 \mathrm{seg}$ & $72^{\circ} / 45 \mathrm{seg}$ & 30 & $72^{\circ} / 10 \min$ & $807 \mathrm{pb}$ \\
\hline OLIGO-gene4R & CCCGAATATCCTGGGCTCT & Reverse & & & & & & & & & \\
\hline OLIGO-gene5F & CCGGAAGAGCCCAGGATA & Forware & OLIGO-gene5 & gDNA & $94^{\circ} / 5 \min$ & $94^{\circ} / 1 \min$ & $60^{\circ} / 45 \mathrm{seg}$ & $72^{\circ} / 1 \min$ & 35 & $72^{\circ} / 10 \min$ & 967 pb \\
\hline OLIGO-gene5R & CCGTTTGGCAGGAATACAT & Reverse & & & & & & & & & \\
\hline
\end{tabular}




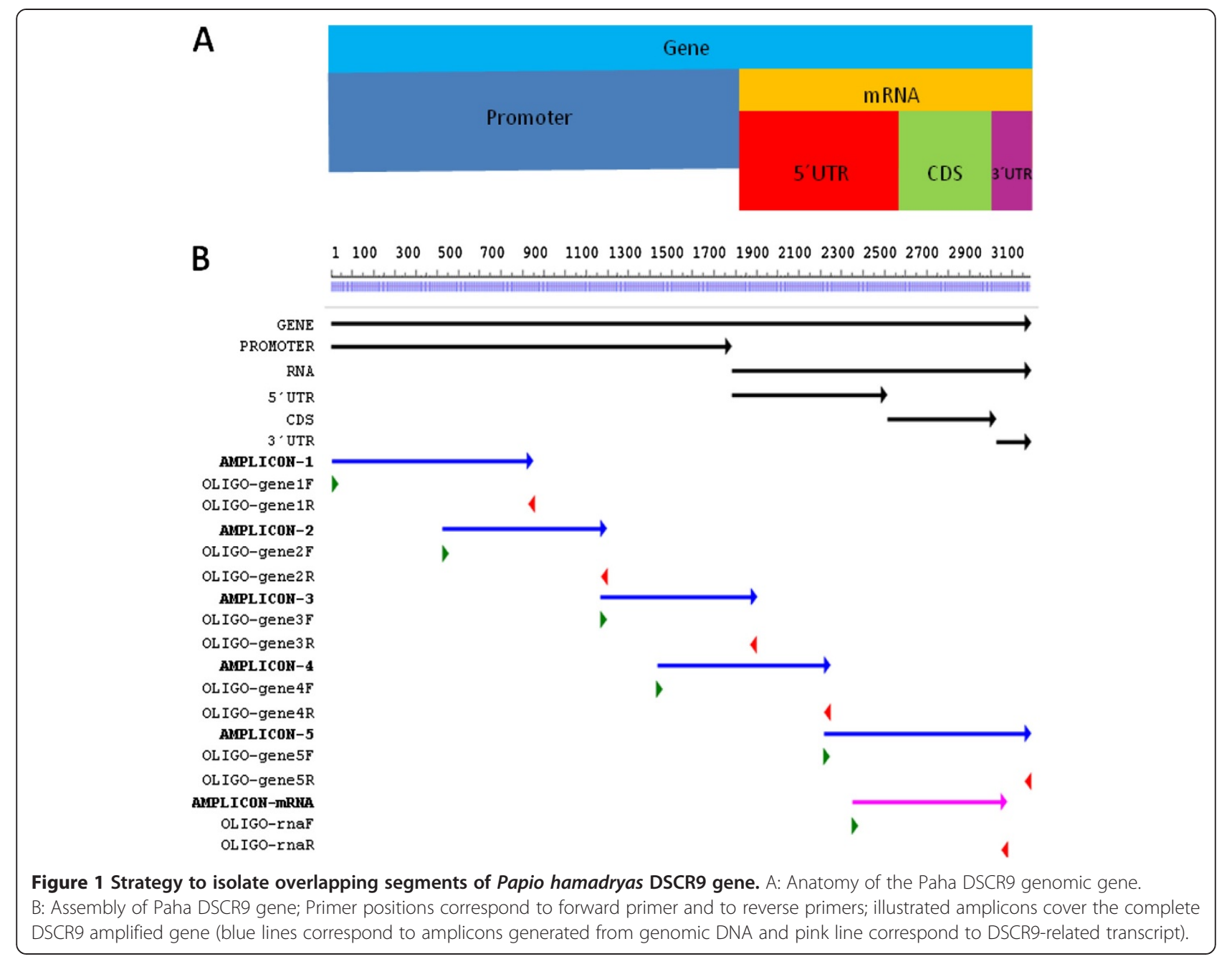

substantial size difference mainly. For example, while the length of gene, putative promoter, messenger RNA (mRNA), 5'-untranslated region (UTR), coding DNA sequence (CDS) and 3'-UTR for baboon are: 3284, 1861, 1423, 754, 505 and 164 bp (base pair), those of the human are: 3385, 1975, 1410, 767, 450 and 193 bp.

\section{DSCR9 gene putative promoter analysis}

Based on the structure of the DSCR9 human gene, we performed the amplification of an upstream region of the transcriptional unit, which we proposed as the putative promoter. The obtained sequence was compared with its counterpart in Hosa [9], which was 93\% identical (see Figure 3). Additional experiments of transcriptional activity are required to validate the promoter activity of this DNA segment.

\section{Papio hamadryas DSCR9 transcript detection}

In order to determine DSCR9 gene expression in baboon, total RNA was extracted from testis, kidney, cardiac, omental fat, skeletal muscle, pancreas, mononuclear cells, liver, and hypothalamus, placenta and ovary tissues. Total RNA was used for cDNA synthesis by RT. For DSCR9 transcript isolation an oligo set was designed consisting of a forward consensus primer (DSCR9-rnaF) hybridizing at 148 bases upstream from the translation initiation codon (AUG) and a reverse primer (DSCR9rnaR) annealing 36 bases after the termination codon (UGA) (positions according to Hosa DSCR9 mRNA [9]). We detected an amplified product in three different tissues: placental, testis and kidney. A single band was amplified in each case. The size of the amplified product (Paha: 726 b) was larger than expected, according to the human sequence (Hosa: $673 \mathrm{~b}$ ). We used amplification of ribosomal RNA $18 \mathrm{~s}$ as positive control for each tissue. Negative and positive controls gave the expected results. Expression in heart, omental fat, skeletal muscle, pancreas, mononuclear cells, liver, and hypothalamus was discarded, at least to the sensitivity levels of the used RTPCR techniques.

The baboon DSCR9 gene sequence, which is also that of its mRNA since it is an intronless gene, was compared 


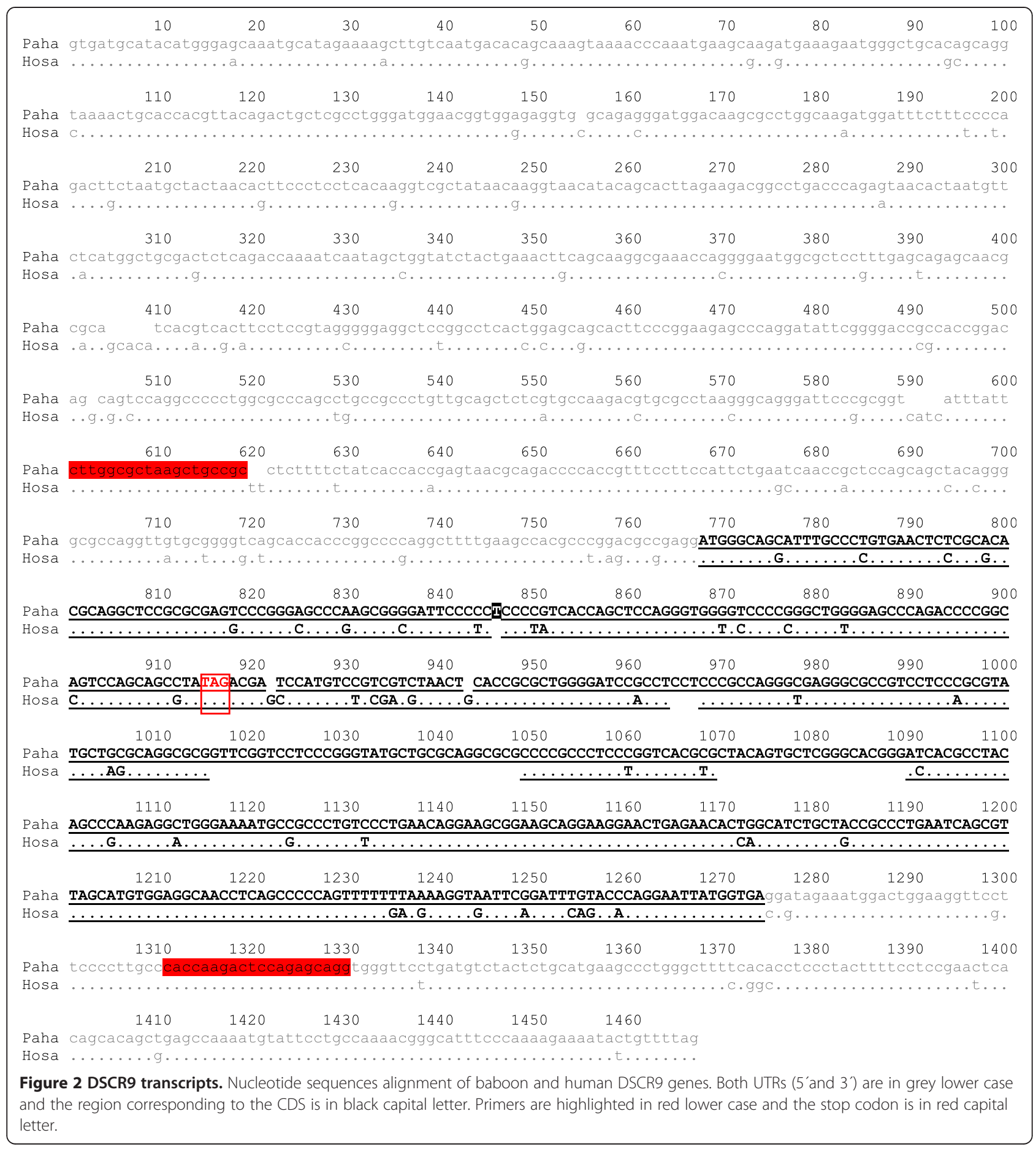

with its Hosa counterpart and found to be $90 \%$ identical. This value decreases to $89 \%$ if just the CDS of both genes are compared. A single thymine nucleotide insertion (underlined in black) results in a premature stop codon (showed in a box), which is predicted to decrease the polypeptide length to 50 aa (see Figure 2). Consequently, from this point on both conceptually translated proteins lose their similarity.

\section{Discussion}

The expression of DSCR9 gene evidenced in baboon's testicular, kidney and placental tissues coincides with previous reports of expression in humans in the former tissue, but differs in that of the later two organs. The sequences of DSCR9 gene transcripts in all baboon tissues were identical and without evidence of alternative splicing, unlike those reported for human in which eight different mRNA 
A

$\begin{array}{llllllllll}-1900 & -1890 & -1880 & -1870 & -1860 & -1850 & -1840 & -1830 & -1820 & -1810\end{array}$ Hosa AGCTGGCACTCCCCAGAATGCGACAATAT---ACAGACATAGGCACAAATTCTGTTTTCATACTTTTCTAAGTACTTAAAACCTCCACAGCATATGTCTT

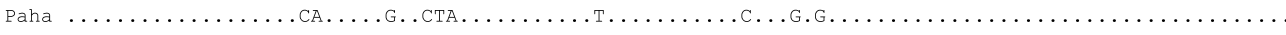

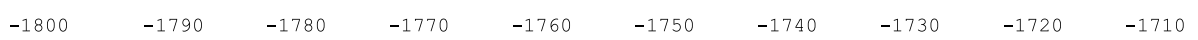
Hosa TTGTATGTTATACACAAGACTGTAAAGAGACTGGCTGGGGTTGGACATGAAAAGCCCTACAAAGTCAGAATCCTGCCGGCCTGGAGCGGGTCTATCCAA

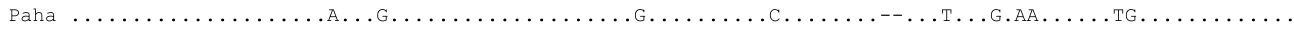

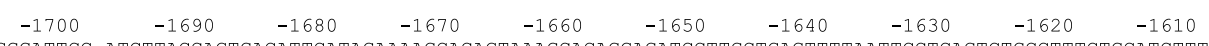
Hosa GGGATTCC-ATCTTACCAGTGACATTCATAGAAAAGCACAGTAAAGCACAGGAGATCCTTGCTGAGTTTTAATTCCTCAGTCTGCCTTTCTGCATCTTTT

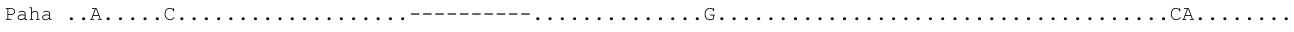

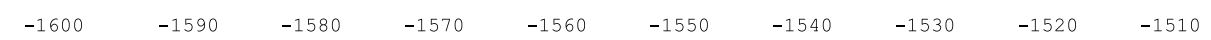
Hosa GAGTGATACACTCTAATAATTTGACTGCATTTTGTGTGAGTATAGCTGGATCCGCTTTGATTCTACAAATTAGGTGCCCTTCTGTTTCTTAGTAATGTCA

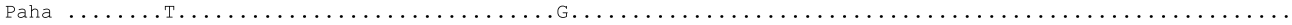

$\begin{array}{llllllllll}-1500 & -1490 & -1480 & -1470 & -1460 & -1450 & -1440 & -1430 & -1420 & -1410\end{array}$ Hosa TATTCTCTGACCACTGTAGCCACTTAAGATAGTCTCAAATATGAATAATTTTCAGTGGCCATAGTGGAGAAGATGCTGACCCAGGAGGCTTATTCTCACC

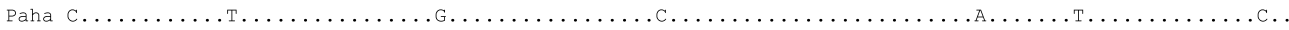

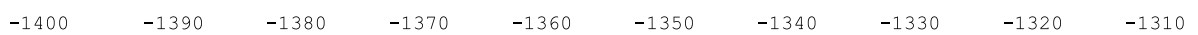
Hosa TCCACCTCTTAGACTCACATGTATGATTTTTTTTTCTCCCTACCAAAGTGGCTAGTTTTGACAGCCTTTAGGTTGCAGAACTGTTTATATTCGAAAGAA

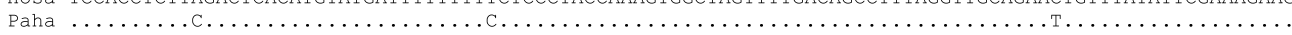
Paha
-130

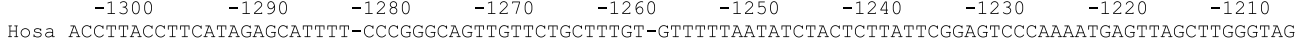

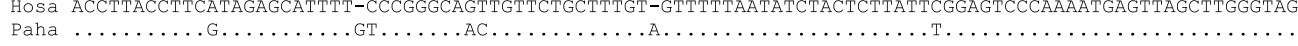

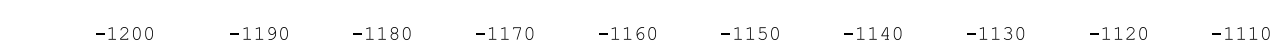
Hosa CTCTCACAATGAAAACTGATTTCTTCGCATAAAACTTTATTCTACCTTTTTGAAAACCAGCTGGAAATGATGAATGGTGGCTTCAACAGTAATGGTTCAC

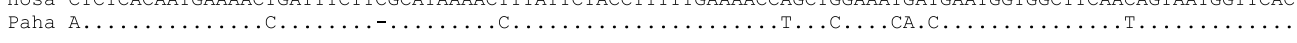

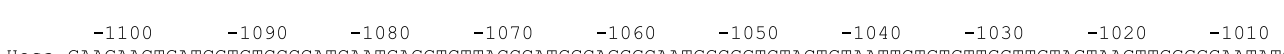
Hosa GAAGAACTGATCGTGTCCCCATCAATGAGGTCTTACCCATGGCAGGGCAATGGCGGTCTACTGTAATTCTGTGTTGGTTGTAGTAAGTTGGGGGAATATC

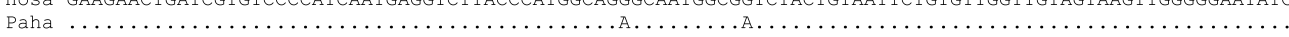

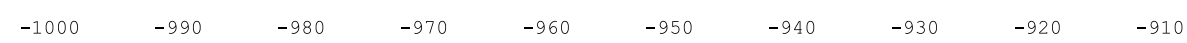
Hosa AGGCCAAGAATCAACAGAGCTACGTGGCTTAGGCAGGTCAGTTTCTCTGTGCCTCAGCCTGCTCACCTGTGAGATGGGATAATAAACACCCCTCAGAAG

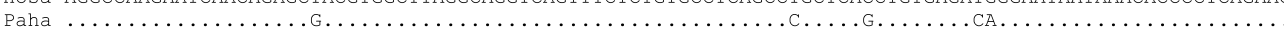

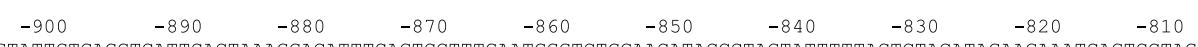
Hosa GTATTGTGAGGTCATTCACTAAAGGACATTTCAGTCCTTTGAATGGGTCTGGAACATACCCTAGTATTTTTACTCTACATAGAAGAATCAGTCCTAGAA

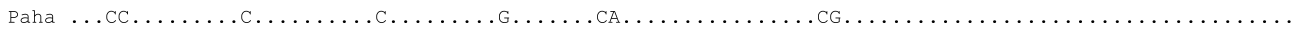

$$
\begin{array}{llllllllll}
-800 & -790 & -780 & -770 & -760 & -750 & -740 & -730 & -720 & -710
\end{array}
$$
Hosa TATAATTAGATCGGACTTTCTGGTCCTTTAATCACTCG-CCTCCTTCCTAAACTGGATCCAGCTGCAAATGATTGCGTTAGTCTCAGGACTTCATTTTCA

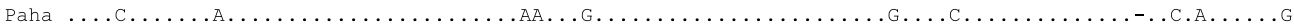

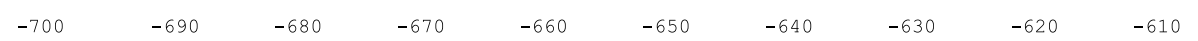
Hosa TTTGACTCAGCTGATCAAAACTGAGACCATTCTGAGGCAGGAGAATAGGGTCTGGAGGCAGTAAACCTAAGCCCAATTCACGCTGACTTCCTAGAACTAA

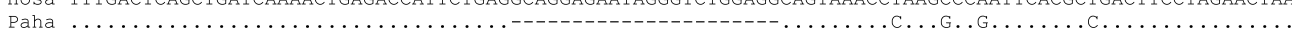

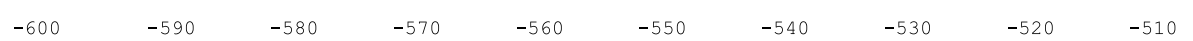

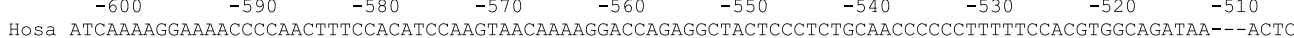

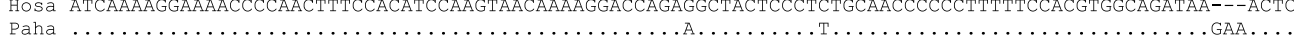

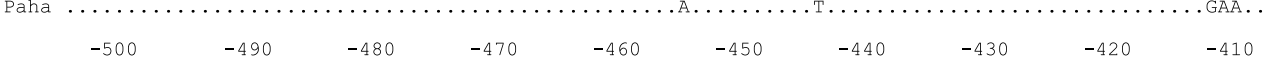

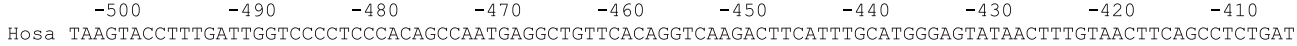

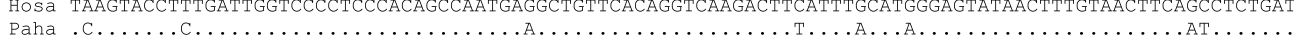
$\begin{array}{lllllllll}-400 & -390 & -380 & -370 & -360 & -350 & -340 & -330 & -320\end{array}$

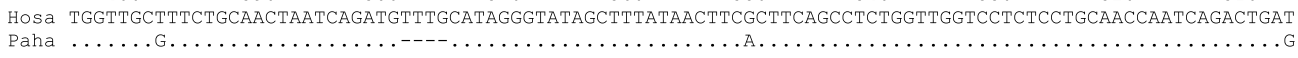

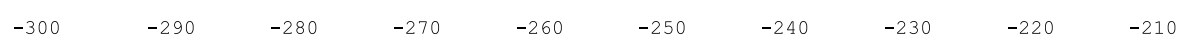
Hosa TATGGTCCACTACTTCATTTACACAAGGTGTACACCAAGTAACCAATGGGAAACCTCTACAGGGTATTTAAATCCCAGAAAATTGTGTCACCGGGCCCTT

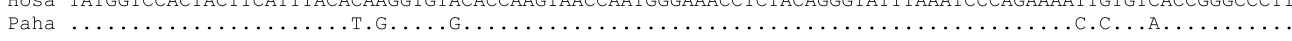

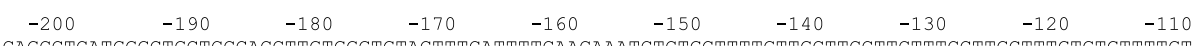

Hosa CAGCCTCATGGGCTGCTCCCACCTTGTGGGTGTACTTTCATTTTCAACAAATCTCTGCTTTTGTTGCTTCCTTCTTTCCTTGCTTTGTGTGTTTTGTCCA

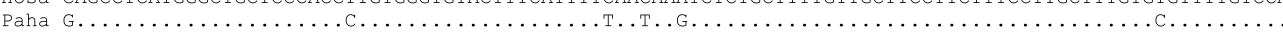

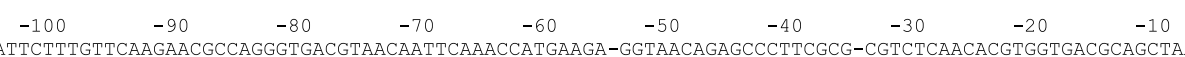
Hosa ATTCTTTGTTCAAGAACGCCAGGGTGACGTAACAATTCAAACCATGAAGA-GGTAACAGAGCCCTTCGCG-CGTCTCAACACGTGGTGACGCAGCTAATA

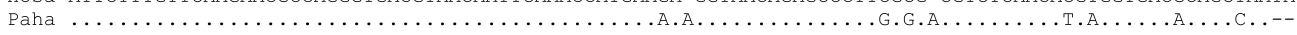

Hosa ACCT Paha...-

B

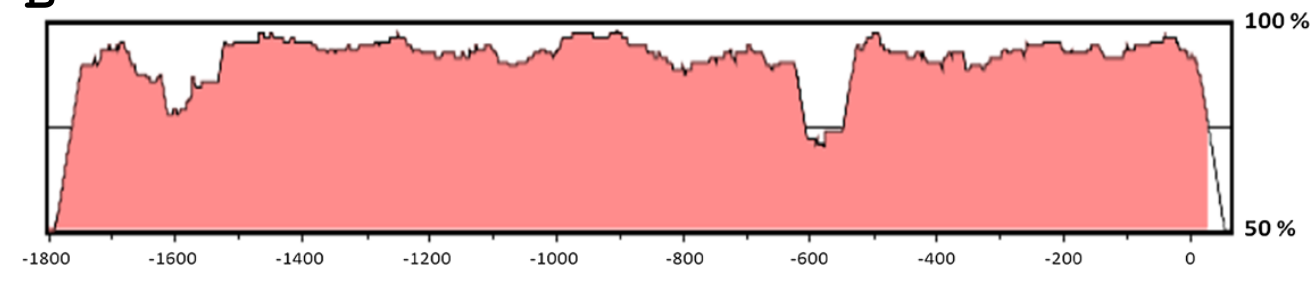

Figure 3 Comparison of DSCR9 promoter of human vs baboon. A: sequence alignment. B: Comparison of the two promoters using the Vista Tool program [13]. 
Table 2 Reported transcripts from nucleotide databases

\begin{tabular}{|c|c|c|c|c|c|c|c|c|c|c|}
\hline \multirow[t]{2}{*}{ Species } & \multicolumn{10}{|l|}{ Tissue } \\
\hline & Testis & Unknown & Liver & Placenta & Kidney & $\begin{array}{l}\text { Skeletal } \\
\text { muscle }\end{array}$ & Spleen & Brain & $\begin{array}{l}\text { Caudate } \\
\text { nucleus }\end{array}$ & Unknown \\
\hline \multirow[t]{2}{*}{ Homo sapiens } & NR_026719* & & AB212291* & & & AB212287* & $\begin{array}{l}\text { AB212 } \\
289^{*}\end{array}$ & $\begin{array}{l}A B 212 \\
290^{*}\end{array}$ & $\begin{array}{l}\text { AK313 } \\
458^{*}\end{array}$ & \\
\hline & & & & & & & $\begin{array}{l}\text { AB212 } \\
288^{*}\end{array}$ & $\begin{array}{l}\text { AB212 } \\
286^{*}\end{array}$ & & \\
\hline
\end{tabular}

Papio anubis

SRR001694**

Macaca fascicularis AB168984*

DC640452***

CJ490857*

Callithrix jacchus

SRR0000079**

SRR000079**

${ }^{*}=$ Core subset of nucleotide sequence records, ${ }^{* *}=\mathrm{SRA},{ }^{* * *}=\mathrm{EST}$ of GenBank at the NCBI.

species have been described (see Table 2). Currently, the predicted DSCR9 protein has not been detected and thus the function of this gene remains unknown. It is hypothesized that allelic variants of the DSCR9 gene may influence the accumulation of connective tissue of the iris resulting in the phenotype of a different eye color [10]. Probably the $D S C R 9$ gene is expressed constitutively in the iris and/or acts in a regulatory manner through RNA interference and/or modifies the expression of other genes in the tissue that is associated with a specific phenotype.

\section{Conclusion}

In our study we found a homologous region to the human DSCR9 gene in the Papio hamadryas genome. We provide evidence of the expression of DSCR9 gene in baboon's testicular, kidney and placental tissues and of lack of expression in heart, omental fat, skeletal muscle, pancreas, mononuclear cells, liver, and hypothalamus. The segments that compose the transcript unit were assigned based on the strategy described previously by Takamatsu, et al. [9]. Experiments like RNA-RACE are necessary to found 5'CAP element and designate the length of the 5'-UTR (size in nucleotides). We proposed our gene elements' nomenclature according to the gene annotation made by Takamatsu et al. [9]. According to our findings, the predicted baboon $5^{\prime}$-UTR has a second ATG sequence that initiates a putative ORF of only three amino acids in length. Then, we agreed with the start codon proposed by Takamatsu et al. [9]. The function of this gene remains unknown, but at least in baboon seems to be dispensable since its corresponding mRNA has a single nucleotide insertion that results in a premature termination of protein. Further studies on the function of this protein in human and other primates are required to understand its role and possible association with the DS phenotype.

\section{Abbreviations}

DS: Down Syndrome; DSCR: Down Syndrome Critical Region; DSCR9: Down Syndrome Critical Region 9; Paha: Papio hamadryas; Hosa: Homo sapiens; b: base; bp: base pairs; PCR: Polymerase Chain Reaction; RT: Reverse Transcription; EST: expressed sequence tag; SRA: Sequence Read Archive;
mRNA: messenger RNA; CDS: coding DNA sequence; UTR: untranslated region.

\section{Competing interests}

The authors do not have any potential or actual personal, political, or financial interest in the material, information, or techniques described in this paper.

\section{Acknowledgements}

The present work was supported by grants from the Mexican Council of Sciences and Technology, CONACyT (U43987-Q), UANL's PAICyT (SA972-04), Research Facilities Improvement Program (C06RR014578, C06 RR13556, C06 RR015456 and C06 RR017515) and from the NIH (PO1 HL028972 and P51 RR013986). IPRS enjoyed an SNI assistantship and a visiting student fellowship from the Department of Genetics at TBRI. The authors gratefully acknowledge the critical reading of the manuscript by Sergio Lozano.

\section{Author details}

${ }^{1}$ Vitaxentrum. Blvd. Puerta del Sol 1005, Colinas de San Jerónimo, Monterrey, Nuevo León 64460, Mexico. ${ }^{2}$ Facultad de Medicina, Departamento de Bioquímica y Medicina Molecular, Universidad Autonoma de Nuevo León, Av. Madero y Dr. Aguirre Pequeño, Col. Mitras Centro, Monterrey, Nuevo León 64460, Mexico. ${ }^{3}$ Auxology and Metabolism Working Group, and Texas Biomedical Research Institute, San Antonio, TX, USA. ${ }^{4}$ Instituto Nacional de Medicina Genómica, Periférico sur 4124. Torre Zafiro II Col. Ex Rancho de Anzaldo, México, DF, Mexico. ${ }^{5}$ Department of Genetics, Texas Biomedical Research Institute, San Antonio, TX, USA.

\section{Authors' contributions}

IPRS and HABS designed the study. IPRS carried out the main laboratory and bioinformatics work; MLGR aided in analyzing the results and drafted the manuscript; MET, AGC and SAC hosted IPRS for baboon tissue processing. IPRS, MET and HABS drafted the manuscript. All authors read and approved the final manuscript.

Received: 21 January 2012 Accepted: 15 June 2012

Published: 15 June 2012

\section{References}

1. Patterson D: Genetic mechanisms involved in the phenotype of Down syndrome. Ment Retard Dev Disabil Res Rev 2007, 13:199-206.

2. Megarbane A, Ravel A, Mircher C, Sturtz F, Grattau Y, Rethore MO, Delabar JM, Mobley WC: The 50th anniversary of the discovery of trisomy 21: the past, present, and future of research and treatment of Down syndrome. Genet Med 2009, 11:611-616.

3. Hattori M, Fujiyama A, Sakaki Y: The DNA sequence of human chromosome 21. Tanpakushitsu Kakusan Koso 2001, 46:2254-2261.

4. McCormick MK, Schinzel A, Petersen MB, Stetten G, Driscoll DJ, Cantu ES, Tranebjaerg L, Mikkelsen M, Watkins PC, Antonarakis SE: Molecular genetic approach to the characterization of the "Down syndrome region" of chromosome 21. Genomics 1989, 5:325-331.

5. Toyoda A, Noguchi H, Taylor TD, Ito T, Pletcher MT, Sakaki Y, Reeves RH, Hattori M: Comparative genomic sequence analysis of the human 
chromosome 21 Down syndrome critical region. Genome Res 2002, 12:1323-1332.

6. Luke S, Gandhi S, Verma RS: Conservation of the Down syndrome critical region in humans and great apes. Gene 1995, 161:283-285.

7. Benirschike K, Bogart MH, McClure HM, Nelson-Rees WA: Fluorescence of the trisomic chimpanzee chromosomes. J Med Primatol 1974, 3:311-314

8. McClure HM, Belden KH, Pieper WA, Jacobson CB: Autosomal trisomy in a chimpanzee: resemblance to Down's syndrome. Science 1969,

165:1010-1012.

9. Takamatsu K, Maekawa K, Togashi T, Choi DK, Suzuki Y, Taylor TD, Toyoda A, Sugano S, Fujiyama A, Hattori M, et al: Identification of two novel primatespecific genes in DSCR. DNA Res 2002, 9:89-97.

10. Liu F, Wollstein A, Hysi PG, Ankra-Badu GA, Spector TD, Park D, Zhu G, Larsson M, Duffy DL, Montgomery GW, et al: Digital quantification of human eye color highlights genetic association of three new loci. PLoS Genet 2010, 6:e1000934.

11. Payton JE, Grieselhuber NR, Chang LW, Murakami M, Geiss GK, Link DC, Nagarajan R, Watson MA, Ley TJ: High throughput digital quantification of mRNA abundance in primary human acute myeloid leukemia samples. $J$ Clin Invest 2009, 119:1714-1726.

12. Ahmed TR, Mordan NJ, Gilthorpe MS, Gillam DG: In vitro quantification of changes in human dentine tubule parameters using SEM and digital analysis. J Oral Rehabil 2005, 32:589-597.

13. Arai S, Hara Y, Mimura K, Nagasawa H, Nishijima Y: Analysis of pigmentation in human skin: quantification of ultraviolet ray images by digital image processing. Int J Cosmet Sci 1989, 11:103-120.

14. Nolano M, Provitera V, Crisci C, Stancanelli A, Wendelschafer-Crabb G, Kennedy WR, Santoro L: Quantification of myelinated endings and mechanoreceptors in human digital skin. Ann Neurol 2003, 54:197-205.

15. Kozak M: An analysis of 5'-noncoding sequences from 699 vertebrate messenger RNAs. Nucleic Acids Res 1987, 15:8125-8148.

16. Kozak M: Downstream secondary structure facilitates recognition of initiator codons by eukaryotic ribosomes. Proc Natl Acad Sci USA 1990, 87:8301-8305.

\section{Submit your next manuscript to BioMed Central and take full advantage of:}

- Convenient online submission

- Thorough peer review

- No space constraints or color figure charges

- Immediate publication on acceptance

- Inclusion in PubMed, CAS, Scopus and Google Scholar

- Research which is freely available for redistribution

Submit your manuscript at www.biomedcentral.com/submit 